\title{
WEIGHT-BEARING CONE BEAM CT SCANS AND ITS USES IN ANKLE, FOOT, AND KNEE: AN UPDATE ARTICLE
}

\section{TOMOGRAFIA COMPUTADORIZADA COM CARGA EM TORNOZELO, PÉ E JOELLHO: UM ARTIGO DE ATUALIZAÇÃO}

\author{
Carlos felipe Teixeira LôBo ${ }^{1}$ (1), Marcelo Bordalo-Rodrigues ${ }^{1}$ (i), \\ WEIGHT-BEARING COMPUTED TOMOGRAPHY INTERNATIONAL STUDY GROUP*
}

1. Universidade de São Paulo, Medical School, Hospital das Clínicas, Orthopedics and Traumatology Institute, São Paulo, SP, Brazil.

\section{ABSTRACT}

Imaging plays a key role in the preoperative diagnosis, surgical planning, and postsurgical assessment of the foot, ankle, and knee pathologies. Interpreting diagnostic imaging accurately is crucial for the clinical practice of orthopedic surgeons. Although among the most used imaging modalities, radiographic assessments are amenable to errors for various technical reasons and superposition of bones. Computed tomography (CT) is a conventional imaging procedure that provides high-resolution images, but fails in considering a truly weight-bearing (WB) condition. In an attempt to overcome this limitation, WB cone beam CT technology has being successfully employed in the clinical practice for the past decade. Besides economically viable and safe, the WB cone beam CT considers WB conditions and provides high-quality scans, thus allowing an equitable and correct interpretation. This review aims to address extensive description and discussion on WBCT, including imaging quality; costs; time consumption; and its applicability in common foot, ankle, and knee, conditions. With this technology increasing popularity, and considering the extensive literature on medical research, radiologists and orthopedic surgeons need to understand its potential applications and use it optimally. Level of Evidence III, Systematic review of level III studies.

Keywords: Tomography, X-Ray Computed. Orthopedics. Weight-Bearing. Foot. Ankle Joint. Knee Joint.
RESUMO

Os exames de imagem são essenciais no diagnóstico, planejamento cirúrgico e avaliação pós-cirúrgica das patologias que envolvem pé, tornozelo e joelho. A interpretação acurada utilizando as tecnologias de diagnóstico por imagem disponíveis é crucial para os cirurgiões ortopédicos na sua prática clínica. Embora as radiografias convencionais estejam entre as modalidades de diagnóstico por imagem mais utilizadas, elas estão sujeitas a erros por várias razões técnicas e sobreposição de estruturas ósseas. Apesar de a tomografia computadorizada (TC) fornecer imagens de alta qualidade, ela falha em não considerar a carga corporal fisiológica. A TC de feixe cônico com carga vem sendo utilizada com sucesso desde a última década, superando a limitação da TC convencional. Além de ser econômica e segura, possibilita a aquisição de imagens de alta resolução, com carga, permitindo, assim, uma interpretação correta e equiparável. O objetivo principal dessa revisão é proporcionar uma discussão e descrição ampla de TC com carga, incluindo qualidade de imagem, custos financeiros, tempo consumido em exames, e suas aplicações em patologias comuns do pé, tornozelo e joelho. A TC com carga vem crescendo em popularidade, e é tema de um número extenso de pesquisas científicas, sendo necessário que radiologistas e cirurgiões ortopédicos entendam suas aplicações para melhor uso futuro. Nível de Evidência III, Revisão sistemática de Estudos de Nível III.

Descritores: Tomografia Computadorizada por Raios X. Ortopedia. Suporte de Carga. Pé. Articulação do Tornozelo. Articulação do Joelho.

Citation: Lôbo CFT, Bordalo-Rodrigues M, Weight-Bearing Computed Tomography International Study Group. Weight-bearing cone beam CT scans and its uses in ankle, foot and knee: an update article. Acta Ortop Bras. [online]. 2021;29(2):105-110. Available from URL: http://www.scielo.br/aob.

\section{Conflict of interests: Cesar de Cesar Netto reports paid consultancy for CurveBeam LLC.} No conflicts for the remaining authors.

The study was conducted at Hospital das Clínicas, Orthopedics and Traumatology Institute, Universidade de São Paulo. Correspondence: Carlos Felipe Teixeira Lôbo. Rua Dr. Ovídio Pires de Campos, 333, São Paulo, SP, Brazil, 05403-010. carlosfelipetl2@gmail.com

\footnotetext{
* Weight-Bearing Computed Tomography International Study Group:

Alexandre Leme Godoy-Santos - Laboratório Prof. Manlio Mario Marco Napoli, Hospital das Clínicas, Faculdade de Medicina, Universidade de São Paulo, São Paulo, SP, Brazil; Riccardo Gomes Gobbi - Laboratório Prof. Manlio Mario Marco Napoli, Hospital das Clínicas, Faculdade de Medicina, Universidade de São Paulo, São Paulo, SP, Brazil; Cesar de Cesar Netto - Department of Orthopaedics and Rehabilitation, University of lowa, lowa City, IA, USA; Arne Burssens - Ghent University Hospital, Gent, Belgium; François Lintz - Ankle and Foot Surgery Center, Clinique de I'Union, Saint Jean, Toulouse, France; Alexej Barg - Department of Orthopaedics, University of Utah, Salt Lake City, Utah, USA.
} 


\section{INTRODUCTION}

Diagnostic imaging provides important information complementary to physical examination, besides aiding in the preoperative planning and postoperative evaluation of the treatment, thus being essential for the orthopedic workup in the foot, ankle, and knee. Radiographs are typically the initial examinations and they should be preferably performed in a weight-bearing (WB) condition to evaluate bone alignment and joint space ${ }^{1}$. Although common and widely used nowadays, radiographs provide two-dimensional (2D) images of three-dimensional (3D) structures, requiring several assumptions and considerations regarding patient positioning, magnification, and image distortions. ${ }^{2}$

Misalignment between the X-ray source and patient positioning may lead to significant varied assessments. ${ }^{3-6}$ Systematic reviews on imaging options for distal tibiofibular syndesmosis and subtalar joint (SJ) found conventional radiography to be the most frequently used imaging modality, but raised concerns about its diagnostic reliability. ${ }^{7,8} \mathrm{~A}$ literature review highlighted the limitations of conventional radiography techniques in providing scans that reflect the complexity of hallux valgus (HV) in 3D, such as sectorized and limited information in different planes, superimposing structures, image magnification, and misalignment between $\mathrm{X}$-ray source and patient positioning. ${ }^{9}$

Studies reported variations in the measurements of coronal alignment of knee joint performed in WB condition and supine position, which may significantly impact the outcomes after total knee arthroplasty or revision surgery if disregarded. ${ }^{10,11}$

Radiographic assessment is the most common test for diagnosing knee osteoarthritis (OA). However, even when performed under optimal acquisition conditions, it is inaccurate and not sensitive enough. ${ }^{12}$ The lack of sensitivity and specificity for detecting OA-associated articular cartilage damage, as well as the poor sensitivity to record variations in follow-up imaging are some of the limitations of radiography. Variations in knee positioning during image acquisition may influence the quantitative measurement of various radiographic parameters, including joint space narrowing. ${ }^{13}$

For offering enhanced bone visualization, computed tomography (CT) is preferable to radiography regarding measurements associated with patellar instability and patellofemoral alignment. However, CT is performed in non-WB supine position, with the knee at full extension and the quadriceps muscles relaxed, imposing a limitation for the technique. ${ }^{14}$

Weight-bearing CT (WBCT) technology combines the benefits of highly detailed CT imaging, enabling a multiplanar and 3D visualization, with WB considerations, thus providing accurate measurements at a comparatively lower dose of radiation exposure. ${ }^{15}$ This review discusses WBCT technology and its applicability, costs, time consumption, and imaging quality of ankle, foot, and knee alignment and their associated pathologies. We conducted a literature search for studies published between 2000-2020 in PubMed and ScienceDirect databases, and relevant studies were retrieved and included in this review. No constraints were imposed on the type of studies included.

\section{Technology and system description}

WBCT employs cone-beam CT (CBCT) technology. Although initially used in dental radiology, the small and compact design with high-quality images of the extremities under WB conditions has gained increasing attention over the past decade. ${ }^{16,17}$ Different from conventional multidetector CT (MDCT), which emits a fan-shaped $\mathrm{X}$-ray beam that traces multiple spiral paths (helical CT) around the patient lying on the moving table, ${ }^{18}$ WB CBCT uses a smaller gantry composed of an X-ray tube emitting a pyramid-shaped X-ray beam (the 'cone') and a large detector panel (Figure 1). ${ }^{18,19}$ Imaging is performed with the patient standing at the center of the machine with the $X$-ray source and the imaging detector at different sides. This tube-detector system executes a single rotation around the patient, ${ }^{18}$ whereby the scan obtains fully volumetric data from multiple projections acquired over a $220^{\circ}$ arc in about $18-20 \mathrm{~s}$, with less radiation exposure time $(<10 \mathrm{~s}){ }^{18,19} \mathrm{~A}$ computer with installed software acquires the data from multiple projections, reconstructs them within 20-120 s, and creates 3D and multiplanar images using algorithms. ${ }^{19}$ Reconstructed images comprise hundreds of slices (> 600 in some machines) of a submillimeter thickness $(0.2 \mathrm{~mm})$, which are uploaded to a picture archiving and communication system (PACS) as a standard digital imaging and communications in medicine (DICOM) CT image stack. These can be further used for multiplanar reformations or volume reconstructions with any DICOM-compatible radiology workstation software (Figure 2). ${ }^{19}$ The software also enables creating digitally reconstructed radiographs in multiple standard projections (such as Anterior-Posterior, oblique, and lateral views). ${ }^{17}$

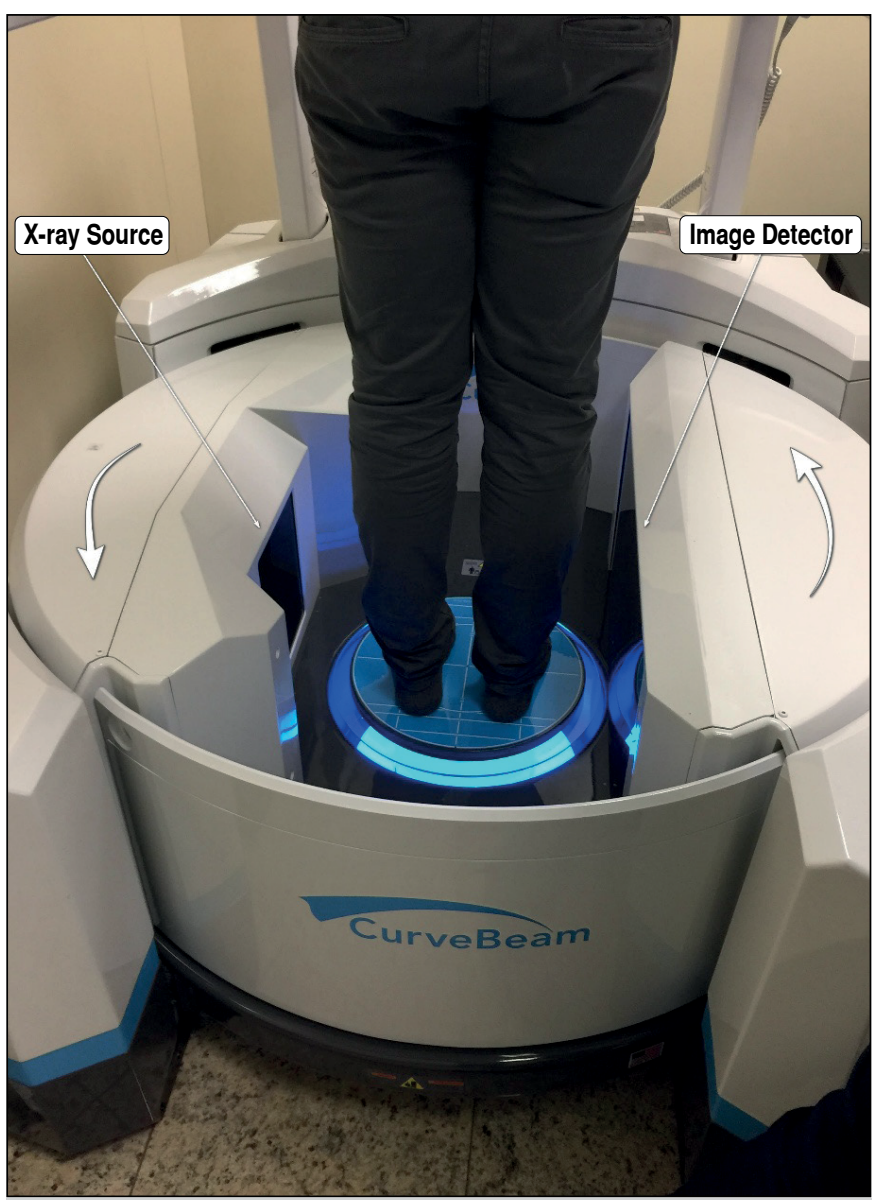

Figure 1. Weight bearing LineUp ${ }^{\circledR}$ cone-beam computed tomography (CT; CurveBeam, Philadelphia, PA, USA). Patient positioning for ankles and feet scan. The patient stands at the center of the machine, with the $\mathrm{X}$-ray source and image detector at opposing sites. The tube-detector system executes a single rotation around the patient. Curved arrows represent the tube-detector system rotational movement. For knee scanning, the gantry raises to the appropriate level and performs a single rotation (not shown). 


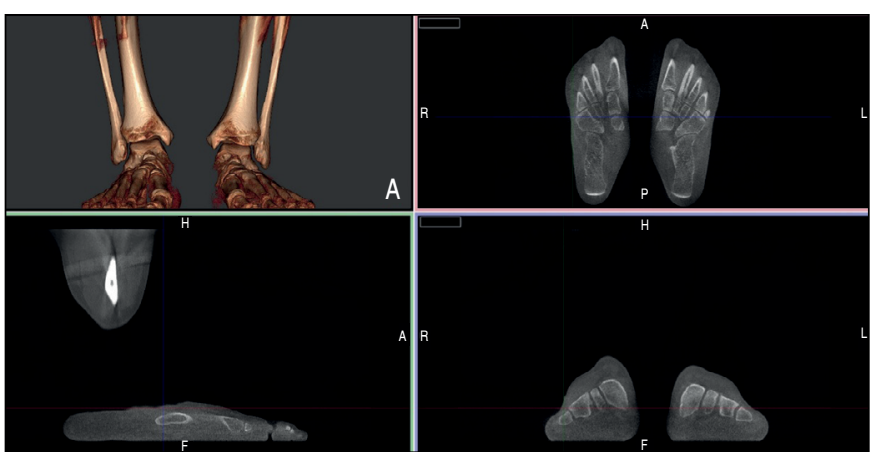

Figure 2. Software user interface, Cubevue ${ }^{\circ}$ (CurveBeam, Warrington, PA, USA) for foot and ankle. The upper-left window represents the volumetric reconstruction, which may be tailored by the user. The remaining windows are multiplanar reconstructions provided by the software. The user can likewise tailor these images and perform measurements.

Several models of WB CBCT devices are available. Whereas some are restricted for imaging of the foot and ankle, others contain a mobile gantry to scan the knees. These devices acquire images not only in WB conditions, but also in seating and even in monopodal WB position.

\section{Radiation dose, imaging time, and cost-effectiveness}

The radiation dose used in WBCT is lower than that of conventional multidetector CT, but higher than that of conventional radiography. Yet, radiographs radiation doses may increase or even equate to those of WBCT depending on additional radiographic series performed, WBCT field of view (FOV), and whether imaging is conducted in a single or both feet. ${ }^{18,20}$ The radiation dose to an organ or tissue is calculated based on the equivalent dose, and its expression in units $\left({\left.\mathrm{J} . \mathrm{kg}^{-1}\right)}^{-1}\right.$ equals the absorbed dose, referred to as sievert (Sv). Whereas for a single-exposure radiograph of the foot the radiation dose is $0.001 \mathrm{mSv}$, for a WB CBCT of the foot/ankle it is $0.01 / 0.03 \mathrm{mSv}$, and $0.07 \mathrm{mSv}$ for a conventional CT of the ankle. In the US, the average background radiation/ year is $3.0 \mathrm{mSv}^{17}$

A study evaluated 11,009 WBCT scans performed by a pioneer institution to investigate radiation dose, time spent, and costeffectiveness in comparison with WB radiograph series and conventional CT without WB. The authors found that WBCT was more cost-effective, generating an overall increase of 51.12 Euros per patient in the institution profit, as well as a 10\% decrease in the yearly average dose and a 77\% decrease in time spent with WBCT when compared to the radiograph/CT group. ${ }^{21}$

\section{Foot and ankle}

WBCT provides high-quality images and diagnostic accuracy, facilitating the assessment of complaints related to bone alignment in the foot and ankle, ${ }^{22}$ such as distal tibiofibular syndesmosis (TFS), SJ, peritalar subluxation, subtalar instability, hindfoot alignment (HA) and associated pathologies, pes cavus and planus, hallux valgus $(\mathrm{HV})$, and pedography. WBCT imaging have also been successfully employed in postoperative evaluation, such as calcaneal osteotomy and $\mathrm{HV}$ correction procedures, and in developing customized medical devices. ${ }^{15,23}$

Studies reported a positive correlation between HA measurements performed using WBCT and clinical measurements. ${ }^{24,25}$ Burssens et al. proposed an evaluation method for HA on WBCT, which combined the talocalcaneal axis and the anatomical axis of the tibia in the coronal plane. The authors found a good correlation with the anatomical tibial axis obtained by full leg radiography, suggesting that the short end of the tibia included in the WBCT imaging can be used to determine HA. ${ }^{24}$ Conversely to previously described constitutional valgus measured by radiographic methods, the WBCT method presented a more neutral hindfoot configuration in a population without suspicion of hindfoot pathology. ${ }^{26}$ By using the WBCT data to create 3D images, Burssens et al. found a good correlation between measurements performed in 2D and 3D images. ${ }^{27}$

Lintz et al. described an efficient 3D biometric and semi-automatic method for calculating $\mathrm{HA}$ based on the torque acting on the ankle joint stemming from body weight and ground-reaction forces. ${ }^{28}$ Instead of the tibia axis, this method uses the forefoot as a reference and measures the offset between the hindfoot-to-forefoot midline and talus, the foot-ankle offset (FAO), with five 3D-points or coordinates - the first and fifth metatarsal head WB point, the calcaneus WB point, and the centermost and highest talus in the coronal and sagittal planes. "Foot length" was established by a line extending from the calcaneus to the midpoint between the first and the fifth metatarsal heads. Between the ground projection of the centermost and highest talus point and the "foot length" line, the "F" perpendicular point of intersection was determined. The FAO is measured as a percentage of the distance between the ground projection of the centermost and highest talus point and $F$ divided by the 'foot length' (Figure 3). When compared to $2 \mathrm{D}$ methods, the $3 \mathrm{D}$ approach to calculate $\mathrm{HA}$ using $\mathrm{FAO}$ is less susceptible to errors related to projection, rotation, and the operator. Lintz et al. found a mean FAO value of $2.3 \% \pm 2.9 \%$ in normal cases, $-11.6 \% \pm 6.9 \%$ in varus cases, and $11.4 \% \pm 5.7 \%$ in valgus cases. ${ }^{28}$

By comparing differences in the distal TFS position, evaluated by the distal fibula displacement in relation to the incisura using WBCT and non-WBCT (NWBCT), a study found a statistically significant external rotation and lateral and posterior translations of the fibula on WB. ${ }^{29}$ Another study also determined TFS differences in asymptomatic patients using CT in WB and non-WB (NWB) conditions. Except for the medial clear space, which was significantly lower on WB images, the author found no statistically significant differences in measurements evaluating fibular diastasis, rotation, and translation relative to the incisura. ${ }^{30}$ According to the author, some conflicting results may be explained by the inclusion of patients presenting post-traumatic conditions that may affect syndesmotic measurements or the use of different imaging equipment. ${ }^{30} \mathrm{~A}$ cadaveric study simulating WB and NWB conditions by load application found no statistically significant difference in the diagnosis of incomplete syndesmosis injuries, but observed a significant benefit for complete injuries. ${ }^{31}$ However, torque application (external rotation of the foot and ankle) might have been change this scenario, as observed by other cadaveric studies that demonstrated its benefits in diagnosing TFS injuries, including incomplete ones. ${ }^{32,33}$ A study conducted with healthy volunteers investigated the dynamics of the distal tibiofibular joint and the talus through WBCT performed in a neutral position and on internal and external rotation of the ankle on WB. ${ }^{34,35}$ In the neutral position, the distal fibula was located primarily in the anterior aspect of the incisura (88\% of the subjects). During external rotation of the talus, it shifted to the posterior aspect in $40 \%$ of the subjects, but did not assume the posterior position in any of the cases during internal rotation. ${ }^{34}$ Between the internal and external rotation of the ankle, the distal fibula showed a $1.5 \mathrm{~mm}$ motion and a $3^{\circ}$ rotation, ${ }^{34}$ whereas the talus showed a $10^{\circ}$ rotation in the ankle mortise. ${ }^{35}$ WBCT was used to establish normal TFS reference values and threshold values for suspected TFS injuring. ${ }^{36}$ The study also found men's Fibulae to be significantly more laterally translated. ${ }^{36}$ 


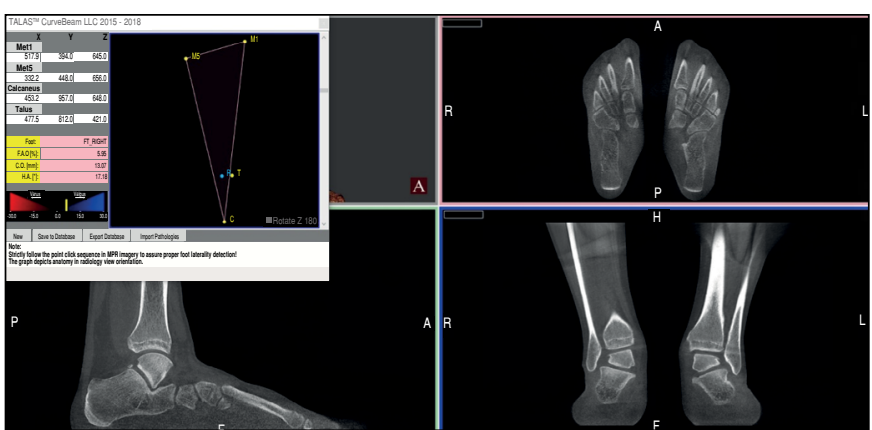

Figure 3. Foot-Ankle Offset (FAO) measurement using the Torque Ankle Lever Arm System (TALAS ${ }^{\circledR}$; CurveBeam, Warrington PA, USA) with Cubevue ${ }^{\circledR}$ software in a patient with pes planovalgus. In this example, the measured FAO is positive, indicating that the center of the ankle joint is positioned medially to the bisecting line of the foot tripod (valgus alignment). Five points (coordinates) are established using the multiplanar reconstruction - the first metatarsal head WB point (M1), fifth metatarsal head WB point (M5), ground projection of the centermost and highest talus point ( $\mathrm{T}), \mathrm{M} 1-\mathrm{M} 5$ equidistant point (E), and a CE line point (foot length) crossed by a perpendicular line that includes T. FAO is measured as a percentage of the TF distance divided by the CE distance (foot length). Using this system, FAO measurement is fast and straightforward.

Del Rio et al. conducted a prospective study assessing the syndesmotic area of 39 patients with ankle instability following acute injury and syndesmotic instability verified by arthroscopy and compared with the contralateral uninjured ankle using WBCT in WB and NWB conditions. The authors found unstable ankles to present a significantly greater diastasis in WB when compared to NWB and to uninjured ankles in WB. Uninjured ankles showed a slight syndesmosis widening, but significantly less pronounced than unstable ankles. ${ }^{37}$ Colin et al. studied the morphology of the posterior facet of the ST joint in 59 asymptomatic subjects using WBCT images and found most of them to be concave (88\%), opposed to the $12 \%$ that were flat $(12 \%)$ on coronal plane images. ${ }^{38}$ The subtalar vertical angle (SVA) was adopted to analyze the orientation of the posterior facet of the SJ. SVA was calculated on the coronal plane, by intersecting a line connecting the medial and lateral border of the posterior facet of the SJ with a vertical line perpendicular to the floor, using a cut in the middle of the SJ as reference. Values lower than $90^{\circ}$ determined varus configuration, and those greater than $90^{\circ}$ were determined valgus configuration. Although SVA values changed according to the localization on facet (anterior, middle, and posterior), $90 \%$ of the subjects presented a valgus orientation. ${ }^{38} \mathrm{SJ}$ orientation may pose a compensatory factor in ankle osteoarthritis, as osteoarthritic varus ankles show a more valgus-oriented posterior facet of the $\mathrm{SJ}^{39}$ and a more severe internal rotation of the talus. ${ }^{40}$

This review will adopt the nomenclature of Progressive Collapsing Foot Deformity (PCFD) instead of adult acquired flatfoot deformity (AAFD), according to recent consensus ${ }^{1}$. A prospective study conducted by de Cesar Netto et al. evaluated 20 patients with PCFD using WBCT in WB and NWB conditions and found a statistically significant difference between them, except for the calcaneal inclination angle (one of the nineteen measurements performed). This result indicates the complexity of the three-dimensional deformity and alterations involving the coronal, axial, and sagittal planes. ${ }^{41}$ Investigators of different expertise levels found WBCT measurements of flexible PCFD to be reliable. ${ }^{41,42}$ Likewise, WBCT was also employed for assessing peritalar subluxation in the context of flexible PCFD, indicating that patients presenting with such condition showed a statistically significant increase in the "uncoverage," implying peritalar subluxation, as well as incongruence of the middle facet of the SJ in relation to the opposing calcaneal articular surface. ${ }^{43}$

Using WBCT, Collan et al. evaluated 10 patients with HV deformity in WB and NWB situations and measured 2D and 3D hallux valgus angles (HVA), intermetatarsal angles (IMA), first metatarsal bone pronation, and first proximal phalanx pronation angles. WB measurements for 2D and 3D HVA, IMA, and proximal phalanx pronation were higher than those found in the control group. The authors also observed a tendency for slight rotation of the first metatarsal bone, but without significant difference among study groups. ${ }^{44}$ Another study comparing HV patients with healthy controls using simulated WBCT conditions reported significant dorsiflexion, supination, and internal rotation of the first tarsometatarsal (TMT) joint in those affected with $\mathrm{HV} .{ }^{45}$ Hypermobility was also shown to continue along the first ray, involving the first metatarsophalangeal, naviculocuneiform, and talonavicular joints. ${ }^{46}$

A prospective study conducted by Conti et al. used pre- and post-surgical WBCT images and WB radiographs to evaluate foot width reduction in 31 feet with HV following a modified Lapidus procedure combined with a modified McBride and Akin osteotomies in most cases. Both WB and WBCT showed a significant reduction in bony and soft tissue foot and no increase in foot width post-surgery. ${ }^{47}$ Lintz et al. performed a retrospective study with a cohort of patients who underwent TAR and had postoperative follow-up WBCT scans to determine the association between periprosthetic cysts and residual malalignment of the hindfoot after total ankle replacement (TAR). The total cystic volume was positively correlated with residual malalignment, measured by the absolute FAO values, with the varus alignment presenting a more medially positioned cyst and the valgus alignment a laterally positioned cyst. ${ }^{48}$

\section{Knee}

Regarding knee evaluation, WBCT has been mostly used in individuals with OA and patellar instability, and for evaluating joint alignment by measurements analogous to radiography and tomography. When compared to NWBCT, WBCT presented significant differences. In patients with OA, WBCT has shown a significant reduction in the medial tibiofemoral compartment joint space width ${ }^{49,50}$ and increased meniscal extrusion when compared with NWBCT ${ }^{49}$ Regarding asymptomatic patients, the above measurements increased in WB and NWB conditions. ${ }^{49}$

WBCT-based 3D color-coded maps of the medial tibial subchondral area based on tibiofemoral joint space widths showed that patients with larger surface areas and narrow joint space width $(<2.0 \mathrm{~mm})$ reported greater functional limitations, based on specialized questionnaires. Although the study found a trend for these patients to report greater pain severity was observed, it was not statistically significant. ${ }^{51}$

When compared with NWBCT, WBCT showed good interrater reliability and significant differences in the assessment of patellofemoral alignment. Imaging performed under full weight-bearing condition at $30^{\circ}$ knee flexion showed statistically worse values in tilt angle, congruence angle, and distance between the tibial tubercle and the center of the trochlear groove (TTTG offset) of patients with acute or chronic patellar instability when compared to routine methods. ${ }^{52}$ A local study used a dynamic CT setting with muscle action across the knee range of motion to assess pre- and post-operative patellofemoral tracking in patients with patelar instability. However, WB condition was unfeasible in this examination. ${ }^{53}$ Although paramount for understanding and planning corrections in patellofemoral pathologies, replicating WB conditions was not really possible before the advent of WBCT. Likewise, a study predominantly conducted with OA patients evaluated knee joint alignment using WBCT and NWBCT in fully extended positions using two musculoskeletal radiologists. 
Both radiologists observed a significant decrease in TTTG offset, but only one found a decrease of the patellar tilt angle. Both radiologists also recorded a significant difference in femorotibial rotation, changing from external rotation of the tibial plateau to the femoral condyles on NWBCT to internal rotation on WBCT..$^{50}$ Given that conventional NWBCT may overestimate TTTG offset due to the supine position in which images are acquired, and thus with relaxed muscles, this is a key information for pre-surgical planning. A study conducted with healthy volunteers with progressive knee flexion angles $\left(0^{\circ}, 30^{\circ}, 60^{\circ}\right.$, and $\left.120^{\circ}\right)$ using WBCT enabled the assessment of tibiofemoral and patellofemoral rotations, patellofemoral distance, TTTG, and tibiofemoral contact points. Although the measurements performed at $120^{\circ}$ flexion were conducted without WB conditions due to technical limitations, the study reached excellent interreader agreement for most measurements. ${ }^{54}$ The internal rotation of the tibia relative to the femur increased alongside the increase of flexion angles, whereas patellofemoral rotation tended to decrease from external to almost horizontal position. TTTG and patellofemoral distance likewise decreased. The tibial tuberosity was observed medially to the trochlear groove at $120^{\circ}$ flexion. To establish contact points of the tibiofemoral joint, the authors divided the medial and lateral tibial plateaus from anterior to posterior, into $\leq 30 \%, 31 \%-60 \%, 61 \%-90 \%$, and $91 \%-100 \%$. The results show that the contact point of the tibiofemoral joint was far anterior $(\leq 30 \%)$ on the medial side at $0^{\circ}$ flexion, shifting posteriorly during flexion
(61\%-90\% at $120^{\circ}$ flexion) and never found at the far posterior (91\%$100 \%$ ). However, regarding the lateral side, the contact point was central $(31 \%-60 \%)$ at $0^{\circ}$ flexion for most volunteers, gradually shifting to posterior during flexion and located more posteriorly than on the medial side $(91 \%-100 \%){ }^{54}$

\section{CONCLUSION}

WBCT is a novel technology that can be used to evaluate feet, ankles, and knees in various circumstances, such as normal alignment, pathologies, and for postoperative follow-up. ${ }^{25}$ Although a relatively new technology, several institutions worldwide have published articles addressing WBCT over the past decade. To improve imaging segmentation, 3D technology has been incorporated to the imaging technique. ${ }^{9,16,17}$ Besides being safe and incurring low radiation exposure, WBCT may also be financially attractive to institutions when compared to conventional radiography and CT scans. This review explained WBCT applicabilities to different locations and pathologies, as well as the various measurements it can provide in relation to other imaging modalities. Studies found WBCT to provide reliable and accurate measurements. Given the broader understanding and growing popularity of WBCT within the literature, musculoskeletal radiologists and orthopedic surgeons must comprehend its features, strengths, uniqueness, and applicability in routine clinical practice.

AUTHORS' CONTRIBUTIONS: Each author contributed individually and significantly to the development of this article. CFTL: designed the study, acquired, analyzed, and interpreted the data, and drafted the article; MB: performed the critical review, approved the final version of the manuscript; ALGS: designed the study, performed the critical review, approved the final version of the manuscript; RGG: performed the critical review, final approved the final version of the manuscript; CCN: performed the critical review; AB: performed the critical review; LF: performed the critical review; AB: performed the critical review.

\section{REFERENCES}

1. Myerson MS, Thordarson DB, Johnson JE, Hintermann B, Sangeorzan BJ Deland JT, et al. Classification and Nomenclature: Progressive Collapsing Foot Deformity. Foot Ankle Int. 2020;41(10):1271-6.

2. Carrara C, Caravaggi P, Belvedere C, Leardini A. Radiographic angular measurements of the foot and ankle in weight-bearing: a literature review. Foot Ankle Surg. 2020;26(5):509-17.

3. Willauer P, Sangeorzan BJ, Whittaker EC, Shofer JB, Ledoux WR. The sensitivity of standard radiographic foot measures to misalignment. Foot Ankle Int. 2014;35(12): 1334-40.

4. Barg A, Amendola RL, Henninger HB, Kapron AL, Saltzman CL, Anderson AE. Influence of ankle position and radiographic projection angle on measurement of supramalleolar alignment on the anteroposterior and hindfoot alignment views. Foot Ankle Int. 2015;36(11):1352-61.

5. Baverel L, Brilhault J, Odri G, Boissard M, Lintz F. Influence of lower limb rotation on hindfoot alignment using a conventional two-dimensional radiographic technique. Foot Ankle Surg. 2017;23(1):44-9.

6. Krahenbuhl N, Akkaya M, Dodd AE, Hintermann B, Dutilh G, Lenz AL, et al. Impact of the rotational position of the hindfoot on measurements assessing the integrity of the distal tibio-fibular syndesmosis. Foot Ankle Surg. 2020;26(7):810-7.

7. Krahenbuhl N, Weinberg MW, Davidson NP, Mills MK, Hintermann B, Saltzman CL, Barg A. Imaging in syndesmotic injury: a systematic literature review. Skeletal Radiol. 2018;47(5):631-48.

8. Krahenbuhl N, Weinberg MW, Davidson NP, Mills MK, Hintermann B, Saltzman CL, Barg A. Currently used imaging options cannot accurately predict subtalar joint instability. Knee Surg Sports Traumatol Arthrosc. 2019;27(9):2818-30.

9. Cesar Netto C, Richter M. Use of advanced weightbearing imaging in evaluation of hallux valgus. Foot Ankle Clin. 2020;25(1):31-45.

10. Leon-Munoz VJ, Lopez-Lopez M, Martinez-Martinez F, Santonja-Medina F. Comparison of weight-bearing full-length radiographs and computed-tomography-scan-based three-dimensional models in the assessment of knee joint coronal alignment. Knee. 2020;27(2):543-51.

11. Gbejuade HO, White P, Hassaballa M, Porteous AJ, Robinson JR, Murray JR Do long leg supine CT scanograms correlate with weight-bearing full-length radiographs to measure lower limb coronal alignment? Knee. 2014;21(2):549-52.

12. Hayashi D, Xu L, Roemer FW, Hunter DJ, Li L, Katur AM, Guermazi A. Detection of osteophytes and subchondral cysts in the knee with use of tomosynthesis. Radiology. 2012;263(1):206-15.
13. Guermazi A, Hayashi D, Roemer FW, Felson DT. Osteoarthritis: a review of strengths and weaknesses of different imaging options. Rheum Dis Clin North Am. 2013;39(3):567-91

14. Tanaka MJ, Elias JJ, Williams AA, Carrino JA, Cosgarea AJ. Correlation between changes in tibial tuberosity-trochlear groove distance and patellar position during active knee extension on dynamic kinematic computed tomographic imaging. Arthroscopy. 2015;31(9):1748-55.

15. Godoy-Santos AL, Cesar Netto C. Weight-bearing computed tomography of the foot and ankle: an update and future directions. Acta Ortop Bras. 2018;26(2):135-9.

16. Lintz F, Cesar Netto C, Barg A, Burssens A, Richter M. Weight-bearing cone beam CT scans in the foot and ankle. EFORT Open Rev. 2018;3(5):278-86.

17. Barg A, Bailey T, Richter M, Cesar Netto C, Lintz F, Burssens A, et al. Weightbearing computed tomography of the foot and ankle: emerging technology topical review. Foot Ankle Int. 2018;39(3):376-86.

18. Carrino JA, Al Muhit A, Zbijewski W, Thawait GK, Stayman JW, Packard N, et al. Dedicated cone-beam CT system for extremity imaging. Radiology. 2014;270(3):816-24.

19. Tuominen EKJ, Kankare J, Koskinen SK, Mattila KT. Weight-bearing CT imaging of the lower extremity. Am J Roentgenol. 2013;200(1):146-8.

20. Ludlow JB, Ivanovic M. Weightbearing $\mathrm{CBCT}$, MDCT, and $2 \mathrm{D}$ imaging dosimetry of the foot and ankle. Int J Diagnostic Imaging. 2014;1(2):1-9.

21. Richter M, Lintz F, Cesar Netto C, Barg A, Burssens A. Results of more than 11,000 scans with weightbearing CT: impact on costs, radiation exposure, and procedure time. Foot Ankle Surg. 2020;26(5):518-22.

22. Richter M, Seidl B, Zech S, Hahn S. PedCAT for 3D-imaging in standing position allows for more accurate bone position (angle) measurement than radiographs or CT. Foot Ankle Surg. 2014;20(3):201-7.

23. Leardini A, Durante S, Belvedere C, Caravaggi P, Carrara C, Berti L, et al. Weight-bearing CT technology in musculoskeletal pathologies of the lower limbs: techniques, initial applications, and preliminary combinations with gait-analysis measurements at the Istituto Ortopedico Rizzoli. Semin Musculoskelet Radiol. 2019;23(6):643-56.

24. Burssens A, Peeters J, Buedts K, Victor J, Vandeputte G. Measuring hindfoot alignment in weight bearing $C T$ : a novel clinical relevant measurement method. Foot Ankle Surg. 2016;22(4):233-8. 
25. Lintz F, Zhang S, Bernasconi A, Zhang J. 3D biometrics for hindfoot alignment using Weight Bearing CT: a prospective assessment of 140 feet. Foot Ankle Orthop. 2018;3(3):1.

26. Burssens A, Van Herzele E, Leenders T, Clockaerts S, Buedts K, Vandeputte G, Victor J. Weightbearing CT in normal hindfoot alignment: presence of a constitutional valgus? Foot Ankle Surg. 2018;24(3):213-8.

27. Burssens A, Peeters J, Peiffer M, Marien R, Lenaerts T, Vandeputte G, Victor J. Reliability and correlation analysis of computed methods to convert conventional $2 \mathrm{D}$ radiological hindfoot measurements to a $3 \mathrm{D}$ setting using weightbearing CT. Int J Comput Assist Radiol Surg. 2018;13(12):1999-2008.

28. Lintz F, Welck M, Bernasconi A, Thornton J, Cullen NP, Singh D, Goldberg A 3D biometrics for hindfoot alignment using weightbearing CT. Foot Ankle Int. 2017;38(6):684-9.

29. Malhotra K, Welck M, Cullen N, Singh D, Goldberg AJ. The effects of weight bearing on the distal tibiofibular syndesmosis: a study comparing weight bearing-CT with conventional CT. Foot Ankle Surg. 2019;25(4):511-6.

30. Shakoor D, Osgood GM, Brehler M, Zbijewski WB, Cesar Netto C, Shafiq B, et al Cone-beam CT measurements of distal tibio-fibular syndesmosis in asymptomatic uninjured ankles: does weight-bearing matter? Skeletal Radiol. 2019;48(4):583-94

31. Krahenbuhl N, Bailey TL, Weinberg MW, Davidson NP, Hintermann B, Presson AP, et al. Is load application necessary when using computed tomography scans to diagnose syndesmotic injuries? A cadaver study. Foot Ankle Surg. 2020;26(2):198-204.

32. Krahenbuhl N, Bailey TL, Presson AP, Allen CM, Henninger HB, Saltzman CL, Berg A. Torque application helps to diagnose incomplete syndesmotic injuries using weight-bearing computed tomography images. Skeletal Radiol. 2019;48(9):1367-76

33. Krahenbuhl N, Bailey TL, Weinberg MW, Davidson NP, Hintermann B, Presson AP, et al. Impact of torque on assessment of syndesmotic injuries using weightbearing computed tomography scans. Foot Ankle Int. 2019;40(6):710-9.

34. Lepojarvi S, Niinimaki J, Pakarinen H, Leskela HV. Rotational dynamics of the normal distal tibiofibular joint with weight-bearing computed tomography. Foot Ankle Int. 2016;37(6):627-35.

35. Lepojarvi S, Niinimaki J, Pakarinen H, Koskela L, Leskel HV. Rotational dynamics of the talus in a normal tibiotalar joint as shown by weight-bearing computed tomography. J Bone Joint Surg Am. 2016;98(7):568-75.

36. Patel S, Malhotra K, Cullen NP, Singh D, Goldberg AJ, Welck MJ. Defining reference values for the normal tibiofibular syndesmosis in adults using weight-bearing CT. Bone Joint J. 2019;101-B(3):348-52

37. Rio A, Bewsher SM, Roshan-Zamir S, Tate J, Eden M, Gotmaker R, et al Weightbearing cone-beam computed tomography of acute ankle syndesmosis injuries. J Foot Ankle Surg. 2020;59(2):258-63.

38. Colin F, Lang TH, Zwicky L, Hintermann B, Knupp M. Subtalar joint configuration on weightbearing CT scan. Foot Ankle Int. 2014;35(10):1057-62.

39. Krahenbuhl N, Siegler L, Deforth M, Zwicky L, Hintermann B, Knupp M. Subtala joint alignment in ankle osteoarthritis. Foot Ankle Surg. 2019;25(2):143-9.

40. Kim JB, Yi Y, Kim JY, Cho JH, Kwon MS, Choi SH, Lee WC. Weight-bearing computed tomography findings in varus ankle osteoarthritis: abnormal internal rotation of the talus in the axial plane. Skeletal Radiol. 2017;46(8):1071-80.
41. Cesar Netto C, Schon LC, Thawait GK, Fonseca LF, Chinanuvathana A, Zbijewski WB, et al. Flexible adult acquired flatfoot deformity comparison between weight-bearing and non-weight-bearing measurements using cone-beam computed tomography. J Bone Joint Surg Am. 2017;99(18):e98.

42. Cesar Netto C, Shakoor D, Dein EJ, Zhang H, Thawait GK, Richter M, et al. Influence of investigator experience on reliability of adult acquired flatfoot deformity measurements using weightbearing computed tomography. Foot Ankle Surg. 2019;25(4):495-502.

43. Cesar Netto C, Godoy-Santos AL, Saito GH, Lintz F, Siegler S, O'Malley MJ, et al. Subluxation of the middle facet of the subtalar joint as a marker of peritalar subluxation in adult acquired flatfoot deformity: a case-control study. J Bone Joint Surg Am. 2019;101(20):1838-44.

44. Collan L, Kankare JA, Mattila K. The biomechanics of the first metatarsal bone in hallux valgus: a preliminary study utilizing a weight bearing extremity $\mathrm{CT}$. Foot Ankle Surg. 2013;19(3):155-61.

45. Geng X, Wang C, Ma X, Wang X, Huang J, Zhang C, et al. Mobility of the first metatarsal-cuneiform joint in patients with and without hallux valgus: in vivo three-dimensional analysis using computerized tomography scan. J Orthop Surg Res. 2015;10:140

46. Kimura T, Kubota M, Taguchi T, Suzuki N, Hattori A, Marumo K. Evaluation of first-ray mobility in patients with hallux valgus using weight-bearing CT and a 3-D analysis system a comparison with normal feet. J Bone Joint Surg Am. 2017;99(3):247-55.

47. Conti MS, MacMahon A, Ellis SJ, Cody EA. Effect of the modified lapidus procedure for hallux valgus on foot width. Foot Ankle Int. 2020;41(2):154-9.

48. Lintz F, Mast J, Bernasconi A, Mehdi N, Cesar Netto C, Fernando C, et al. 3D, Weightbearing topographical study of periprosthetic cysts and alignment in total ankle replacement. Foot Ankle Int. 2020;41(1):1-9.

49. Thawait GK, Demehri S, Almuhit A, Zbijweski W, Yorkston J, Del Grande F, et al. Extremity cone-beam CT for evaluation of medial tibiofemoral osteoarthritis: Initial experience in imaging of the weight-bearing and non-weight-bearing knee. Eur J Radiol. 2015;84(12):2564-70.

50. Hirschmann A, Buck FM, Fucentese SF, Pfirrmann CWA. Upright CT of the knee: the effect of weight-bearing on joint alignment. Eur Radiol. 2015;25(11):3398-404

51. Kothari MD, Rabe KG, Anderson DD, Nevitt MC, Lynch JA, Segal NA, et al. The relationship of three dimensional joint space width on weight - bearing CT with pain and physical function. J Orthop Res. 2020;38(6):1333-9.

52. Marzo J, Kluczynski M, Notino A, Bisson L. Comparison of a novel weightbearing cone beam computed tomography scanner versus a conventional computed tomography scanner for measuring patellar instability. Orthop J Sports Med. 2016;4(12):1-7.

53. Gobbi RG, Demange MK, Avila LFR, Araujo Filho JAB, Moreno RA, Gutierrez MA, et al. Patellar tracking after isolated medial patellofemoral ligament reconstruction: dynamic evaluation using computed tomography. Knee Surg Sports Traumatol Arthrosc. 2017;25(10):3197-205.

54. Hirschmann A, Buck FM, Herschel R, Pfirrmann CWA, Fucentese SF. Upright weight-bearing $\mathrm{CT}$ of the knee during flexion: changes of the patellofemoral and tibiofemoral articulations between 0 and 120 . Knee Surg Sports Traumato Arthrosc. 2017;25(3):853-62 